\title{
POESÍA Y MUERTE: EL ORFISMO DE HUMBERTO DÍAZ-CASANUEVA
}

\author{
POETRY AND DEATH: HUMBERTO DÍAZ- \\ CASANUEVA'S ORPHISM
}

\section{POESIA E MORTE: O ORFISMO DE HUMBERTO DÍAZ-CASANUEVA}

Diego Sanhueza Jerez*

\section{RESUMEN}

En este texto se realizará un análisis filosófico de la poesía de Humberto DíazCasanueva. Nuestro propósito general consiste en descubrir sus motivos esenciales, aquellos que la dotan de una forma única dentro del panorama de las letras chilenas. Siguiendo una indicación del propio autor, diremos que su poesía es "órfica", y esto implica una relación directa con la muerte. Nuestra propuesta consiste en discernir dos momentos en este orfismo: danza y tartamudeo, y en desarrollar la idea de cómo esta poesía alcanza su forma definitiva en el segundo de estos momentos.

PALABRAS CLAVE

Muerte, Poesía, Orfismo, Sentido, Tartamudeo.

\section{ABSTRACT}

The article presents a philosophical analysis of the poetry of Humberto Díaz-Casanueva. Thus, the purpose is to reveal his main motivations, those that made of his poetry unique within Chilean Literature. Following a hint of the poet himself, it is argued that

* Doctor en Filosofía de la Universidad Andrés Bello, Chile (2014).

Correo electrónico: pielago123@gmail.com

ORCID:0000-0002-5755-6427

Artículo recibido el 30 de noviembre de 2015 y aprobado para su publicación el 15 de agosto de 2016. 
his poetry might be considered as "Orphic", which entails a direct link with death. It is also proposed that two moments might be distinguished in such an Orphism: dancing and stuttering, and that such a poetry reaches its final form with the latter.

\section{KEY WORDS}

Death, Poetry, Orphism, Meaning, Stuttering.

\section{RESUIMO}

Neste texto será realizada uma análise filosófica da poesia de Humberto DíazCasanueva. Nosso propósito geral consiste em descobrir seus motivos essenciais, aqueles que a dotam de uma forma única no panorama das letras chilenas. Seguindo uma indicação do próprio autor, diremos que sua poesia é "órfica", e isso implica uma relação direta com a morte. Nossa proposta consiste em discernir dois momentos nesse orfismo: dança e gaguejo, assim como abordar a maneira em que essa poesia atinge sua forma definitiva no segundo desses momentos.

\section{PALAVRAS-CHAVE}

Morte, Poesia, Orfismo, Sentido, Gaguejo. 


\section{Introducción}

$\mathrm{H}$ umberto Díaz-Casanueva (1906-1992) debe ser uno de los poetas más importantes de Chile, y, a la vez, uno de los menos leídos. En el año 1971 -en pleno gobierno socialista de Allendele fue concedido el Premio Nacional de Literatura; pero ello no significó necesariamente una difusión más amplia de su obra. Sus lectores han sido siempre tan fieles como escasos, y los trabajos académicos sobre su significación no abundan, así como tampoco sus las reediciones. Amigo de los grandes poetas chilenos de la primera mitad del siglo XX como Pablo Neruda, Gabriela Mistral y Vicente Huidobro. Sus libros -que a veces incluyen hermosos trabajos colaborativos con artistas visuales- son verdaderamente difíciles de conseguir, y su precio alcanza a veces sumas exorbitantes. En definitiva, un panorama nada alentador para aquel que se quiera familiarizar con esta obra singular e interesante.

El propósito de nuestro artículo será, desde una perspectiva filosófica, realizar un análisis general de su obra que coloque de relieve sus motivos principales, desde un examen que tome en consideración el conjunto de su producción y que intente descifrar su significado. Vamos a enfatizar en todos los elementos difíciles y oscuros que se evidencian en su obra poética para presentar una explicación sobre las características que, en nuestra opinión, representan esta "dificultad" que se desprende en último término de su íntima relación con la muerte. Orfismo será precisamente el nombre que el poeta le va a dar a esta manera de entender el acto poético, esta insalvable relación con la muerte. ¿Cuáles son, entonces, las características de este orfismo?

\section{La muerte despierta}

Ya que la poesía de Díaz-Casanueva es órfica, y ello implica una insoslayable relación con la muerte, examinemos en primer lugar esta noción en su poesía ${ }^{1}$. Con el objeto de contar con un buen soporte teórico, recurriremos

1 En palabras de E. Minard, la muerte es uno de los temas transversales en la obra de nuestro 
primero a los análisis que, sobre este tema, ha desarrollado Heidegger en Ser y tiempo. Estos análisis, lo sabemos, fueron muy familiares a Díaz-Casanueva, ya que fue alumno del filósofo alemán en los años 30. Posteriormente, revisaremos la noción de muerte en su poesía, sobre todo en el poemario que está íntegramente atravesado por este problema, La estatua de sal (1947).

\subsection{La muerte en Ser y tiempo}

Partamos con algunas consideraciones preliminares. ¿Cómo solemos entender la noción de "muerte"? Probablemente nadie objetaría una respuesta como la siguiente: la muerte representa el fin de la vida. ¿Qué significa, entonces, la expresión "fin"? En el parágrafo 48 de Ser y tiempo, Heidegger distingue dos significados de este vocablo: fin entendido como "término" y fin entendido como "conclusión" o "consumación". El filósofo

ilustra el primer caso con el ejemplo de la lluvia que "cesa"; y el segundo, con el del cuadro que, luego de la última pincelada, está "terminado". Pues bien, es evidente que a nosotros nos interesa el primer caso, pues la muerte representa el dejar de existir. Según esto, "vida" y "muerte" serían nociones que se excluyen mutuamente: mientras la primera es, la segunda no es, y cuando la segunda es, la primera ya no puede ser. Como se sabe, así es como lo argumenta Epicuro en la Carta a Meneceo.

Este modo de entender la muerte -el de Epicuro- es lo que Heidegger denomina técnicamente "haber-llegado-al-fin": la muerte como punto final del cual, en definitiva, nada podemos saber. Heidegger se opone a esta caracterización desarrollando la idea del "estar vuelto hacia el fin". Escribe en Ser y tiempo: "El terminar al que se refiere la muerte no significa un haber-llegado-al-fin (Zu-Ende-sein), sino un estar vuelto hacia el fin (Sein zum Ende) de parte de este ente" (266). ¿Qué diferencia existe entre estas dos maneras de aproximarse a la muerte?

poeta: "Hay ahí [en el tema de la muerte] en verdad una especie de corriente que atraviesa toda la obra, desde el primer libro de poemas, sin que aflore el menor escollo susceptible de desviarla por un instante de su curso" (105). 
Como ya dijimos, para el haber-llegado-al-fin -desde Epicuro- no existe relación alguna entre el existente y la muerte: cuando uno es la otra no es, y viceversa. Por el contrario, el "estar vuelto hacia el fin" -desde Heidegger- se define precisamente como una relación entre el existente y su propia muerte. ¿Qué relación? No nos podemos relacionar con la muerte misma, pero si con su posibilidad. En efecto, esta posibilidad está siempre presente en nuestra vida: ella tiene su propia consistencia, su propio espesor. Con esta curiosa presencia entramos en contacto mientras estamos vivos, y solo mientras lo estamos. Su peculiaridad radica en que se trata de una posibilidad que solo puede ser posibilidad, pues su realización eliminaría al sujeto que debería experimentarla como "realizada". Esto es lo que Heidegger, en el parágrafo 53, denomina técnicamente como: "[...] adelantarse a la posibilidad [Vorlaufen in die Möglichkeiet]" (262); es decir, relacionarse con un posible que insiste en su carácter virtual. Por lo mismo, su experiencia se resuelve en la experiencia de una irrealidad, un vacío, una nada.

\subsection{La "muerte despierta" de Humberto Díaz-Casanueva}

Pues bien, esta noción de "muerte" es la que aparece en la obra de DíazCasanueva y, con mucha insistencia, en Estatua de sal. Allí el poeta se refiere con toda claridad a una muerte que hace "acto de presencia" en vida del poeta: ella "[...] vive mientras estamos vivos" (113). También: "[...] la muerte está conmigo ahora y siempre" (117). Aquí la muerte no es, pues, tan solo el fin del ser humano, sino su posibilidad experimentada en vida. Hay una fórmula de Díaz-Casanueva que, en nuestra opinión, resume acabadamente esta situación. Escribe el poeta: "Mi muerte futura está despierta" (106). La muerte de Díaz-Casanueva es su muerte futura, la muerte que aún tiene que llegar; pero esta muerte futura está ahora despierta. De esta manera, el ser humano hace la experiencia de la muerte "antes" de que ella efectivamente llegue: "Su rostro amarillo traspasado a flechazos / contempla la muerte antes de tiempo" (25)².

2 Este modo de entender la muerte -estar vuelto hacia la muerte, muerte despierta- también está presente en los análisis de E. Minard. La especialista habla de una "muerte primera", y señala que ella "prefigura con antelación la obra destructora de la muerte" (54). Según su análisis, se experimenta esta "muerte primera" fundamentalmente en un doble registro: como petrificación del alma y como fragmentación del cuerpo. Nosotros nos extenderemos 


\subsection{Angustia y petrificación del alma}

La muerte es una posibilidad siempre latente para el ser humano, pero solo en algunas circunstancias se nos hace totalmente manifiesta. Sobre este punto, anota el poeta en La estatua de sal: "Esta doble-muerte o muertevida es una manera de ser encubierta por nuestra vida cotidiana y que bajo la influencia de épocas turbadas, sale como busto" (9). La mayoría del tiempo no pensamos en la muerte, preferimos omitir un tema tan macabro. Pero a veces las circunstancias nos obligan; la muerte hace acto de presencia cual si fuera un "busto", y nos interpela. Pues bien, ¿̇qué es lo que se experimenta cuando se experimenta la muerte? Lo sabemos: una

suerte de nada. El correlato subjetivo de esta experiencia es aquello que Heidegger denomina angustia y Díaz-Casanueva, petrificación del alma.

La angustia es un sentimiento muy peculiar. Si no pudiéramos tener ninguna relación con la nada, entonces todo sentimiento negativo vinculado con ella sería realmente injustificado. Recuérdese el argumento de Epicuro en la Carta a Meneceo: "El recto conocimiento de que la muerte no es nada en relación con nosotros hace gozosa la condición mortal de nuestra vida" (410). A su vez, si la nada fuera la presencia de algo, de un objeto con tales o cuales características hostiles, entonces -expresado en términos técnicos- el sentimiento correspondiente debería ser el miedo, y no la angustia: el miedo es siempre miedo ante un ente amenazante. Solo en la angustia se hace patente la muerte en tanto que nada ${ }^{3}$.

Por su parte, Díaz-Casanueva piensa el sentimiento de angustia bajo la figura de la petrificación del alma. Según consta en el epígrafe de Estatua de sal, el poeta está pensando en el mito bíblico de Lot, cuya mujer Edith, fue transformada en estatua de sal por desobedecer el mandato de Yahveh y mirar hacia atrás, es decir, mirar la destrucción -"la nada"- de Sodoma. Siguiendo con la analogía, el alma que siempre tiene la posibilidad de

en este escrito sobre el primer punto. Sobre el segundo punto, que también es interesante, remitimos a las páginas correspondientes de Minard (53-56 y 62-63).

3 Para la angustia en Heidegger, véase la conferencia ¿Qué es metafísica? 
la muerte puede, bajo ciertas circunstancias, mirarla directamente y experimentar su perturbadora presencia. La petrificación de su alma será la consecuencia de este encuentro. Leamos las elocuentes palabras de Díaz-Casanueva estampadas en el prólogo a Estatua de sal:

El alma mira hacia atrás y queda inmóvil frente a las mareas destructoras: forma aparente sobre una sustancia condenada. Y lo que parece expansión del ser es sorbo de aguas profundas que producen la nada y lo que se intuye como trascendencia, es fuga. Las propias lágrimas disuelven. Encontramos extraños a los vivos y el mundo se deshace como la nieve sobre el mar (10).

Por supuesto, la angustia es la experiencia de la posibilidad de la muerte, y no la muerte "misma". En la angustia, participamos de aquello que nos rechaza: morimos en vida, y seguimos respirando. La petrificación del alma, consecuencia directa de nuestro contacto con la nada, hace que el sujeto experimente inmediatamente su finitud como una exposición al sinsentido.

\section{Orfeo}

Como vimos en el apartado anterior, la muerte forma parte estructural del ser humano y su experiencia -angustia, petrificación- expone al sujeto al peligro del sinsentido. En estos parajes, el peligro que evidentemente nos acecha es el del pesimismo absoluto: una visión tanatocéntrica que condena todo al despeñadero del nihilismo. ¿Por qué vivir si todos moriremos indefectiblemente? ¿Por qué hacerlo si estamos condenados a la angustia? En este contexto, sin embargo, asoma la posibilidad del sentido; posibilidad que, además, se le confía a la poesía. ¿Qué entender, entonces, por esta? En uno de sus textos en prosa, compilados en Prosa escogida, Díaz-Casanueva da una respuesta tajante: "[...] el trabajo poético es un ejercicio órfico" (116). Si la poesía es órfica, entonces, ¿qué es el orfismo?

Nos parece que el "ideario órfico" de nuestro poeta se resume perfectamente en la cita de Rilke que Díaz-Casanueva utiliza como epígrafe para el tercer canto de La estatua de sal. Allí podemos leer: "Sólo aquel que alzó la 
lira / también entre sombras / puede expresar, presintiéndolo, / el elogio infinito. / Sólo aquel que comió con los muertos / la amapola que ellos poseen, / no volverá a perder jamás / el más leve de los sonidos" (43) ${ }^{4}$.

En esta cita, notamos que los versos están estructurados al modo de una condición. Parafraseando: solo aquel que tuvo contacto con la negatividad -sombras, amapola de los muertos- puede cantar. Así, resulta que, según el orfismo, el secreto del canto está de alguna manera ligado a la experiencia de lo negativo. Pues bien, la máxima negatividad se encuentra en la experiencia de la nada misma, allí donde el hombre mira frente a frente a la muerte despierta. Por lo tanto: solo quien haya hecho la experiencia de la (propia) muerte puede cantar, o formulado aún de otra manera: la exposición al sinsentido es condición de posibilidad del sentido.

Ahora bien, ćcómo explicarse esto? La respuesta que da el orfismo parece ser la siguiente: la posibilidad del sentido y la del sinsentido, si bien lógicamente son antitéticas, existencialmente son solidarias. En el fondo, la "vida" -el canto, el sentido, etc.- se resuelve en un rechazo a la muerte, y solo puede ejercer este rechazo quien está originariamente expuesto a ella. Estos seres somos evidentemente nosotros: finitos, mortales, perecederos. Siguiendo esta misma hipótesis, un ser que no estuviera expuesto a la negatividad -Dios, por decir algo- tampoco podría acceder al sentido.

\section{Danza y tartamudeo}

Ya lo sabemos: el canto es básicamente órfico, y el orfismo se resuelve en cierta connivencia polémica con la muerte. En Díaz-Casanueva, esta connivencia puede asumir al menos dos formas: una anterior y otra posterior a Los penitenciales. En efecto, y como ya muchos especialistas lo han constatado ${ }^{5}$, se produce en este libro un fuerte cambio de estilo, y este cambio, sugerimos nosotros, tiene que ver con una modificación

4 El fragmento corresponde al soneto IX dela primera parte de Sonetos a Orfeo de Rilke. La traducción se la debemos con alta probabilidad al mismo Díaz-Casanueva.

5 Sobre este punto, véase: Del Re (LII), Droguett (154), Armand (171), Herrera (s/n), Minard (196) y Schopf (25). 
en la estrategia poética, a saber: pensar de manera ligeramente distinta la relación entre nada/sinsentido y el canto/sentido. En lo que sigue, revisaremos estas dos estrategias. Llamaremos a la primera poética de la danza y a la segunda, poética del tartamudeo.

\subsection{Poética de la Danza}

La danza, motivo de ascendente claramente nietzscheano, es fundamental en la poética anterior a Los penitenciales. Su rendimiento no solo se circunscribe a la poesía, sino que es utilizada con un claro peso ontológico, vale decir, con la intención de describir la realidad misma. Hasta donde sabemos, esta idea aparece por primera vez en el Blasfemo coronado. Allí anota el poeta: "la presencia de las cosas siento como una misteriosa danza inmóvil" $(90)^{6}$.. El verso intenta describir la presencia de las cosas, su núcleo ontológico. Esta característica se incrementa progresivamente en los libros posteriores La estatua de sal y La hija vertiginosa.

Pues bien, la importancia de la danza consiste en que permite concebir la inmanencia terrenal como una dimensión que, si bien está traspasada de negatividad, es también, y por la misma razón, una dimensión caracterizada por movimiento, la transformación y la creatividad. En La estatua de sal, la danza consagra alegremente la transitoriedad finita: "sólo la danza multiplica el Uno inmóvil y lo fugitivo / de este modo permanece” (37).

En el mismo libro, aparece claramente la idea de que el poeta debe danzar para vencer la muerte: "El cantor trata de desasirse de sus muertos y comienza otra vez la danza mortal y la transfiguración de las estatuas" (9). En La hija vertiginosa, la niña baila y, al hacerlo, niega la muerte: "Tú aplastas la serpiente que me da la palidez" (7). El poeta le pide a esta niña que le ayude a cantar: "Sean tus pies las letras de mi canto" (51). Como se puede apreciar, se trata de un verdadero triunfo de la vitalidad. De hecho, su poesía de esta época se caracteriza por una exuberancia en las imágenes y un rico despliegue de palabras. El mejor ejemplo de ello es

6 Aquí citamos sin embargo la reedición hecha en el año 1981. 
El blasfemo coronado, libro en prosa construido a base de largas frases llenas de sustantivos, adjetivos, complementos directos e indirectos, etc.

\subsection{Poética del Tartamudeo}

La hija vertiginosa es un texto que está íntegramente dominado por la idea de "redención" de la existencia a través de la danza. Pero 6 años después, cuando Díaz-Casanueva publicó Los penitenciales, la atmósfera fue enteramente distinta: el estilo del poeta se volvió vuelto seco, hosco y fragmentario. ¿Por qué ha ocurrido esto? Para aproximarnos a este asunto tomemos el texto que aparece en una de las solapas de la primera edición de Los penitenciales:

[...] Pude tal vez darle vino al canario, contentarme con el rocío y afinar mi poesía hasta convertirla en canción inofensiva. Pero me han brotado estos Penitenciales, estas barbas de eremita ciudadano: fulguraciones y cegueras, cifras del ser, coloquios de la inocencia y la memoria, tartamudeos de un lenguaje demasiado sumido en sus raíces $[\ldots](\mathrm{s} / \mathrm{n})$.

Si nos centramos directamente en aquello que nos interesa, el poeta indica que su poema es el "tartamudeo de un lenguaje demasiado sumido en sus raíces". Detengámonos un poco en esta idea. ¿̇No es acaso altamente paradójica? Uno esperaría que un lenguaje sumido en sus raíces fuera un lenguaje rico, exuberante, "bailarín", etc. Uno esperaría que aquí las raíces fueran el "origen", y que el contacto con este origen se tradujera en una plenitud de inspiración, y no en un tartamudeo. ¿Cómo explicarse esta curiosa circunstancia?

Tenemos que recordar que para el orfismo de Díaz-Casanueva, la raíz del canto se encuentra en la muerte: "sólo puede cantar el que está expuesto a su daño". Aquí todo ocurre como si el poeta ya no quisiera alejarse danzarinamente de la muerte, sino aproximarse tartamudeando a ella. ¿Por qué? Nuestra hipótesis es que el poeta intenta acercarse al punto en que no hay palabra ni canto, y justamente allí -en el silencio de la muerte - ensayar el canto. El poeta quiere identificar el momento exacto en que el 
sentido surge del sinsentido, el canto del silencio, la vida de la muerte. En palabras de Lavín, en Díaz-Casanueva habría "la necesidad de ir hacia lo oscuro, lo innominado, lo misterioso, para emprender luego la asunción rumbo a la claridad" (4). Ello implica, sin embargo, que el canto estará extremadamente cerca de aquello que lo silencia, y que, por lo mismo, se desplegará con extrema dificultad: será tartamudeo.

Este afán por estar cerca del sinsentido va a traer importantes consecuencias en el estilo del poeta: su anatomía general se verá drásticamente modificada. Una de las cuestiones más sobresalientes es el nuevo lugar que esta poesía le da a los espacios en blanco. Sobre este punto ha dicho Armand que:

La dispersión tipográfica, patente sobre todo a partir de Los penitenciales, facilita una cabal visualización topológica del poema y contribuye así a una captación más inmediata y más henchida de resonancia. La palabra surge en medio del silencio; ese silencio significativo queda añadido al texto mediante la dispersión (el blanco) $\mathrm{y}$ tiene funcionalidad de signo (170-171).

Si retomamos los términos de nuestro análisis previo, el blanco de la página es el equivalente visual de la muerte despierta, y esta, a su vez, es el suelo en el que se deslizarán los pies entintados de la bailarina. Pero esta danza ya no será una danza triunfante de vitalidad, sino el esbozo frágil y tembloroso de una danza demasiado cerca de su petrificación y desmoronamiento.

\subsection{Proyección}

A partir de Los Penitenciales, el orfismo de Díaz-Casanueva alcanza su forma definitiva. El sol de lenguas también es un hito importante en este trayecto, porque aquello que en Los penitenciales se ha llevado a cabo performativamente alcanza aquí una dimensión metapoética. En efecto, en este nuevo libro se tematiza directamente el origen del canto: por el sol de lenguas, indica el poeta, "brota el canto" (59). Pero este sol de lenguas no es -como pudiera pensarse- el "reverso de la muerte" (Foxley 35), sino 
otro nombre para la muerte. Ya el anterior libro de Díaz-Casanueva, Sol ciego, nos debiera haber hecho notar que la muerte es un "sol ciego", un "sol estéril" (22). En Sol de lenguas, también encontramos la expresión "sol tiznado" (33).

Así, un rasgo nuevo que encontramos en el Sol de lenguas es la atribución de cierta agresividad al trabajo del poeta. En efecto, si la escritura órfica se realiza siempre ante o contra la nada y esta -en su dureza, en su impenetrabilidad- puede ser caracterizada como una piedra; entonces hacer poesía consiste en raspar, rayar, picar esa piedra: "Soy el picapedrero del Sol" (63). Y más adelante: "salen los perforadores del Sol" (97). Esta violencia se incrementará en los libros posteriores. En El hierro y el hilo, por ejemplo, leemos: "Escribo cicatrices" (29), "no son palabras/ son raspaduras" (124), "lo que yo escribo/ son tajos" (122). Vox tatuada es el último hito en este viaje, momento en que la dispersión tipográfica se incrementa aún más. Ahí podemos leer: "no soy capaz / sino de un silencio magullado" (29).

\section{Conclusión}

Para terminar, hagamos un pequeño resumen y saquemos algunas conclusiones. En el primer apartado de este escrito se estableció una relación entre la muerte y el ser humano. Se trataba precisamente de una relación, desde Heidegger y no de una "no-relación", como enEpicuro. En la experiencia directa de la nada, el alma se petrificaba rozando el sinsentido. En el segundo apartado, vimos que este sujeto expuesto al sinsentido es precisamente el que puede cantar. Ahora bien, el orfismo no solo constataba un hecho, sino que decretaba una causa: el sujeto puede cantar porque está sometido a la negatividad. En efecto, el canto es anulación de la nada, y esto solo puede hacerlo quien esté originariamente expuesto a ella.

Siguiendo a Díaz-Casanueva, a esta doctrina poética le dimos el nombre de orfismo y, en el tercer apartado, discernimos dos estrategias órficas: de un lado la danza, de otro el tartamudeo. En la primera, la producción 
de sentido consiste pura y simplemente en el rechazo de la nada. En el tartamudeo, sin embargo, ocurría algo decisivo: el poeta se percata de que el rechazo de la nada -paradójicamente- la necesita. Desde este momento, en Los penitenciales, el poeta no buscará simplemente alejarse del sinsentido, sino aproximarse frenéticamente a él, y allí ensayar el sentido. El poema ya no será solamente poema, ni siquiera uno que tenga entre sus "temas" predilectos el de la muerte; el poema se esforzará por incorporar performativamente la muerte en su propia anatomía, como se evidencia en el uso de los espacios en blanco. Por esta misma razón, no se resolverá en un canto fácil sino en un tartamudeo, un canto que está estructuralmente gravado por su propia imposibilidad.

\section{Lista de referencias}

Díaz-Casanueva, Humberto. La estatua de sal. Santiago de Chile: Editorial Nascimiento, 1947.

. La hija vertiginosa. Santiago de Chile: Editorial Nascimiento, 1954.

. Los penitenciales. Roma: Editorial Carucci, 1960.

. Sol ciego. Santiago de Chile: Grupo Fuego, 1966.

. Sol de lenguas. Santiago de Chile: Nascimiento, 1970.

. El hierro y el hilo. Toronto: Editorial Oasis, 1980.

. El blasfemo coronado. México: Editorial Oasis, 1981.

- Vox tatuada. Santiago de Chile. Editorial Universitaria, 1991.

. La medusa. Santiago de Chile: Cuarto propio, 2006.

. Prosa escogida. Santiago de Chile: Das Kapital Ediciones, 2015.

Armand, Octavio. "Apuntes sobre la poesía de Humberto Díaz-Casanueva". Cuadernos Hispanoamericanos 361 (1975): 167-176.

Del Re, Ana María. Introducción a Obra poética. Caracas: Ayacucho, 2010.

Droguett, Carlos. "Poesía de Humberto Díaz Casanueva". Revista Atenea 391 (1961): 150-157.

Epicuro. "Carta a Meneceo". Revista Onomazein 4 (1999): 403-425.

Godoy, Miguel Ángel. Elegía de la ausencia y el rescate. Santiago de Chile: Editorial Nascimiento, 1981.

Heidegger, Martín. Ser y tiempo. Santiago de Chile: Editorial Universitaria, 2002. 
. Hitos. Madrid: Alianza Editorial, 2008.

Herrera, Ricardo. Las marcas del éxtasis. Buenos Aires: Editorial el Imaginero, 1983.

Jiménez, José Olivio. Prólogo a Antología poética. Madrid: Ediciones Cultura Hispánica, 1986.

Lavín, Hernán. "Humberto Díaz-Casanueva: poesía-tatuaje". Noticias de la última hora [Santiago, Chile] 23 Enero 1971: 4.

Minard, Evelyne. La poesía de Humberto Díaz-Casanueva. Santiago de Chile: Editorial Universitaria, 1988.

Foxley, Carmen. Introducción a Vigilia por dentro. Réquiem. Los penitenciales. Santiago de Chile: Editorial Universitaria, 1998.

Schoft, Federico. Introducción a La Medusa. Santiago de Chile: Cuarto Propio, 2006. 